\title{
Synaptic Estrogen Receptor- $\alpha$ Levels in Prefrontal Cortex in Female Rhesus Monkeys and Their Correlation with Cognitive Performance
}

\author{
Athena C. J. Wang, ${ }^{1}$ Yuko Hara, ${ }^{1}$ William G. M. Janssen, ${ }^{1}$ Peter R. Rapp, ${ }^{2}$ and John H. Morrison ${ }^{1}$ \\ ${ }^{1}$ Department of Neuroscience, Mount Sinai School of Medicine, New York, New York 10029, and ${ }^{2}$ Laboratory of Experimental Gerontology, National \\ Institute on Aging, Biomedical Research Center, Baltimore, Maryland 21224
}

In rat hippocampus, estrogen receptor- $\alpha(\mathrm{ER}-\alpha)$ can initiate nongenomic signaling mechanisms that modulate synaptic plasticity in response to either circulating or locally synthesized estradiol (E). Here we report quantitative electron microscopic data demonstrating that ER- $\alpha$ is present within excitatory synapses in dorsolateral prefrontal cortex (dlPFC) of young and aged ovariectomized female rhesus monkeys with and without $\mathrm{E}$ treatment. There were no treatment or age effects on the percentage of excitatory synapses containing ER- $\alpha$, nor were there any group differences in distribution of ER- $\alpha$ within the synapse. However, the mean size of synapses containing ER- $\alpha$ was larger than that of unlabeled excitatory synapses. All monkeys were tested on delayed response (DR), a cognitive test of working memory that requires dIPFC. In young ovariectomized monkeys without E treatment, presynaptic ER- $\alpha$ correlated with DR accuracy across memory delays. In aged monkeys that received E treatment, ER- $\alpha$ within the postsynaptic density $(30-60 \mathrm{~nm}$ from the synaptic membrane) positively correlated with DR performance. Thus, although the lack of group effects suggests that ER- $\alpha$ is primarily in synapses that are stable across age and treatment, synaptic abundance of ER- $\alpha$ is correlated with individual performance in two key age/treatment groups. These data have important implications for individual differences in the cognitive outcome among menopausal women and promote a focus on cortical estrogen receptors for therapeutic efficacy with respect to cognition.

\section{Introduction}

In recent years, studies of rodent hippocampus have highlighted the importance of the estrogen receptors (ER), particularly ER- $\alpha$, as mediators of synaptic plasticity (Spencer et al., 2008; Brinton, 2009). ER- $\alpha$ has been localized within synapses in rodent hippocampus (Milner et al., 2001; Adams et al., 2002; Ledoux et al., 2009), where it likely directly impacts synaptic function without requiring the traditional genomic actions of estrogen receptors. It appears that ER- $\alpha$ can modulate synaptic function and behavior even in the absence of circulating gonadal estradiol, in response to estradiol synthesized within neurons (Hojo et al., 2004, 2008; Rune and Frotscher, 2005). Although ER- $\alpha$ has been directly implicated in hippocampus-dependent cognitive performance (Foster et al., 2008), other ERs such as ER- $\beta$ and GPR30 may also contribute (Liu et al., 2008; Spencer et al., 2008; Brinton, 2009).

Animal models have demonstrated mostly neuroprotective actions of estradiol (Spencer et al., 2008; Frick, 2009), but a few

Received June 21, 2010; revised Aug. 3, 2010; accepted Aug. 5, 2010.

This work was supported by National Institutes of Health Grants AG16765 and AG00647, and supported in part by the Intramural Research Program of the National Institute on Aging. We thank Dr. Wendy Lou for expert assistance with the statistical analyses. We also thank Tweithy Oung, Anne Canfield, Don Canfield, Mary Roberts, Sania Fong, Deborah Kent, and Heather McKay for technical assistance. In addition, we thank Drs. Mark Baxter and Bruce McEwen and Erik Bloss for critical discussion and helpful comments on the manuscript, and Dr. Patrick Hof for neuroanatomic expertise and helpful discussions throughout this project.

Correspondence should be addressed to Dr. John H. Morrison, Department of Neuroscience, Box 1065, Mount Sinai School of Medicine, One Gustave L. Levy Place, New York, NY 10029. E-mail: john.morrison@mssm.edu.

DOI:10.1523/JNEUROSCI.3192-10.2010

Copyright $\odot 2010$ the authors $\quad 0270-6474 / 10 / 3012770-07 \$ 15.00 / 0$ have shown neurodamaging effects in ischemic stroke models (Selvamani and Sohrabji, 2010). Human studies have been less consistent, perhaps due to variability in the timing and formulations of treatments relative to menopause (Sherwin and Henry, 2008; Maki and Sundermann, 2009). Recent analyses of the effects of estradiol (E) treatment on aged nonhuman primates (NHPs) have extended the relevance of animal studies to menopause and cognitive aging in women (Rapp et al., 2003; Hao et al., 2006, 2007; Morrison et al., 2006; Voytko et al., 2009). The NHP studies have been particularly important in demonstrating that dorsolateral prefrontal cortex (dlPFC) is a key target of E, which did not emerge from the rodent studies yet is highly relevant to humans where PFC and related functions also appear to be particularly sensitive to E (Joffe et al., 2006; Brann et al., 2007). We previously reported two key observations using delayed response (DR), a task that is particularly sensitive to age-related decline and that requires area 46 of the dlPFC (Gallagher and Rapp, 1997). First, that young ovariectomized (OVX) rhesus monkeys perform equally well whether administered $E$ or vehicle (V). Second, that aged OVX animals with E perform similarly to young adults with or without E, whereas OVX, vehicle-treated, aged animals display significant DR impairment (Rapp et al., 2003). Reconstructions of pyramidal neurons in area 46 showed that $\mathrm{E}$ increased the density of small, thin spines in both young and aged monkeys (Hao et al., 2007). However, this effect of E occurred against a background of age-related loss of small, thin spines, such that the density of this spine class was especially impoverished in aged V-treated monkeys (Hao et al., 2007). Given the 
importance of synaptic ER- $\alpha$ with respect to E effects in rodent hippocampus, we investigated whether it was present in dlPFC synapses, the potential effects of age and $\mathrm{E}$ on its distribution, and the potential links between synaptic ER- $\alpha$ and cognitive performance in the same monkeys used for the studies described above.

\section{Materials and Methods}

Animals and hormonal screening

Twelve young adult (age range, 9 years \pm 7 months) and 14 aged (age range, 22 years \pm 7 months) female rhesus monkeys (Macaca mulatta) were used in this study. The same monkeys were subjects in our previous investigation of cognitive performance and neuronal morphometric analyses (Rapp et al., 2003; Hao et al., 2006, 2007). All monkeys were singly housed in colonies of $\sim 40$ individuals (water and monkey chow were provided in excess of nutritional needs) at the California National Primate Research Center, University of California, Davis, CA. Animals underwent tests of cognitive function, including DR, before perfusion. The aged females in these studies were generally premenopausal or perimenopausal (Gilardi et al., 1997) before surgical OVX. All experiments were conducted in compliance with the National Institutes of Health Guidelines for the Care and Use of Experimental Animals and approved by the Institutional Animal Care and Use Committee at the University of California, Davis.

\section{Ovariectomy and estradiol cypionate replacement}

All animals received bilateral OVX and were randomly assigned to agematched OVX $+\mathrm{V}$ and OVX $+\mathrm{E}$ groups. After an average post-OVX interval of $30 \pm 1.7$ weeks (mean \pm SEM), half of the monkeys in each age group received $100 \mu \mathrm{g}$ of estradiol cypionate $(100 \mu \mathrm{g} / \mathrm{ml}$ sterile peanut oil, i.m.; Pharmacia) in a single injection every 3 weeks, regardless of weight. OVX $+\mathrm{V}$ age-matched monkeys were provided an equivalent volume (i.e., $1 \mathrm{ml}$ ) of $\mathrm{V}$ injection according to the same schedule. Treatment extended over 2-3 years of behavioral testing. $\mathrm{E}$ and $\mathrm{V}$ injections were coded and administered in a blinded manner until all experiments were completed, with the blind codes retained through all microscopic analyses. Serum E values and urine levels of E metabolites were measured at multiple time points. As published previously for the same animals as those examined here (Rapp et al., 2003; Shideler et al., 2003; Hao et al., 2007), OVX reduced serum and urinary E to approximately zero. Estradiol cypionate injection provided every $21 \mathrm{~d}$ in treated monkeys (group $\mathrm{OVX}+\mathrm{E}$ ) produced a rapid rise in circulating $\mathrm{E}$ compared with $\mathrm{V}$-treated animals (group OVX $+\mathrm{V}$ ), which peaked within $24 \mathrm{~h}$ at levels comparable to preovulatory values in intact females, followed by decline to baseline over the next several days. Behavioral testing and endocrine treatments were continued up to the time of perfusion.

\section{Perfusion and tissue processing}

Perfusion and dissection. All animals were perfused $24 \mathrm{~h}$ after the last $\mathrm{E}$ or $\mathrm{V}$ treatment. They were anesthetized with ketamine hydrochloride (25 $\mathrm{mg} / \mathrm{kg}$ ) and pentobarbital sodium (20-35 mg/kg, i.v.), and perfused as described previously (Hao et al., 2007). The brain was subsequently removed from the skull and dissected, including the entire region comprising the principal sulcus (Brodmann's area 46) in the frontal block. The frontal block was postfixed for $6 \mathrm{~h}$ at $4^{\circ} \mathrm{C}$ in $4 \%$ paraformaldehyde and $0.125 \%$ glutaraldehyde in PBS and then cut serially on a vibratome. Series of $1.3-\mathrm{mm}$-thick sections, which contained two $400-\mu \mathrm{m}$-thick and ten $50-\mu \mathrm{m}$-thick sections, throughout area 46 were collected for electron microscopy with intervening sections used for immunohistochemistry and intracellular injections of Lucifer yellow (Hao et al., 2007).

Postembedding immunogold. Freeze substitution and low-temperature embedding of the specimens was performed as described previously (Adams et al., 2001, 2002; Yildirim et al., 2008), modified from previous reports (van Lookeren Campagne et al., 1991; Hjelle et al., 1994; Chaudhry et al., 1995). Ultrathin sections from layer III of area 46 were cut by a diamond knife on a Reichert-Jung ultramicrotome and mounted on nickel 300 hexagon mesh grids (Electron Microscopy Sciences) for immunogold analysis, as performed in our laboratory previously (Adams et al., 2001, 2002, 2004; Park et al., 2008). The mesh grids with ultrathin sections for immunolabeling studies were treated with $0.1 \%$ sodium borohydride and $50 \mathrm{~mm}$ glycine, washed with $0.3 \%$ saline $/ 0.005 \mathrm{~m}$ Tris (TBS), and then incubated in TBS containing 2\% human serum albumin at room temperature for $30 \mathrm{~min}$. Sections were incubated with primary antibody against ER- $\alpha$ (HC20, dilution 1:800; Santa Cruz Biotechnology) overnight, washed, and incubated in secondary gold-tagged $(10 \mathrm{~nm})$ antibody (Electron Microscopy Sciences) in TBS with $2 \%$ human serum albumin and polyethylene glycol (20,000 Da, $5 \mathrm{mg} / \mathrm{ml})$. Sections were washed and dried, counterstained with $1 \%$ uranyl acetate, and viewed on a Jeol 1200EX electron microscope. Images were captured using the Advantage CCD camera (Advanced Microscopy Techniques). Control experiments were performed in which the primary antibody was omitted or coincubated with a blocking peptide, and no immunogold labeling was observed in either case.

\section{Quantitative EM analyses}

Analysis of percentage of axospinous synapses labeled for ER- $\alpha$. For each monkey, 10 micrographs from each of 10 gridded hexagons were taken at $7500 \times$ (total of 100 micrographs). The first hexagon $\left(\right.$ area $=8740 \mu \mathrm{m}^{2}$ ) was chosen randomly from the mesh grid. Nonoverlapping images were taken systematically starting at one point and progressing clockwise within the hexagon until 10 images were captured. Ninety micrographs from the subsequent nine hexagons were captured similarly. Although some hexagons were adjacent to one another, they were separated by at least $25 \mu \mathrm{m}$ (grid bar width). This imaging method assured a collection of a representative sample of a vast area of PFC area 46. All images contained two or more axospinous synapses, structures that have been shown to be most vulnerable to the effects of age and ovariectomy (Hao et al., 2007). Any synaptic profile that contained at least two gold particles in the presynaptic or postsynaptic region (i.e., in the terminal, synaptic cleft, postsynaptic density, or spine head) was considered positive for ER- $\alpha$. There were 250-400 synapses examined per animal in the analysis. All axospinous synapses fell into one of four categories: (1) gold-labeled perforated synapses, (2) unlabeled perforated synapses, (3) gold-labeled nonperforated synapses, and (4) unlabeled nonperforated synapses. Perforated synapses were defined by the presence of a discontinuity in the PSD. Analyses of perforated synapses based on single sections result in a significant underestimation because approximately half of perforated synapses appear nonperforated when examining only one section (data not shown). However, PFC perforated synapse counts based on single sections versus serial sections show a significant correlation (Pearson correlation, $r=0.948 ; p=0.000029$ ). Thus, this underestimation applies across all animals and is unlikely to bias the outcome of group comparisons or correlations.

Synaptic bin analysis of ER- $\alpha$. The immunogold particle density and distribution was analyzed using software developed in our laboratory (SynBin) (Adams et al., 2001) based on principles regarding proximity to membranes articulated by Blackstad and colleagues (Blackstad et al., 1990; Ruud and Blackstad, 1999). Bin sizes and targeted synaptic domains were established prospectively, with the bins generally established in reference to the presynaptic and postsynaptic membranes associated with the synapse (described below). The program analyzes the resulting data map and then assigns each gold particle to a given bin. It also recorded the postsynaptic density (PSD) length of each synapse. We also measured PSDs of unlabeled synapses using Photoshop and calibrated the measurements according to the same scale used in the SynBin program. A detailed analysis of gold particle distribution was conducted for 50 randomly chosen axospinous synapses per animal. Only synapses with clearly delineated classic synaptic structures, such as presynaptic and postsynaptic membranes, synaptic vesicles, a synaptic cleft, and PSD, were used for quantitative analysis. Thirty nanometers was chosen for the bin width because it assures high resolution well within the theoretical resolving power of EM (i.e., $25 \mathrm{~nm}$ ). For this analysis, presynaptic labeling was not broken down into finer bins, but postsynaptic labeling was separated into the following: (1) two PSD bins, the first one $0-30 \mathrm{~nm}$ from the inner leaflet of the postsynaptic membrane and the second 30-60 nm from the postsynaptic membrane; (2) side bins that were 15 $\mathrm{nm}$ lateral to both of the PSD bins; (3) the synaptic cleft; and (4) a cytoplasmic bin that included gold particles $>60 \mathrm{~nm}$ from the postsynaptic membrane (i.e., the spine core). Particles within the $0-30 \mathrm{~nm}$ do- 

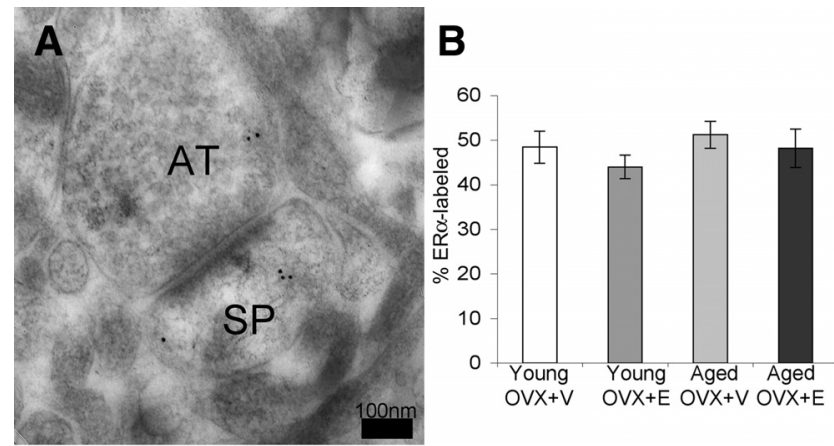

C
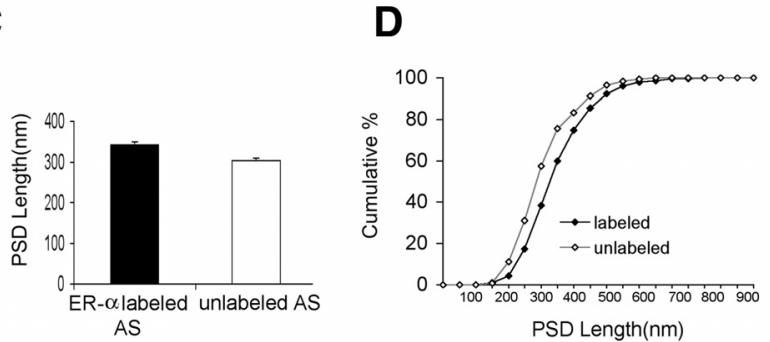

E

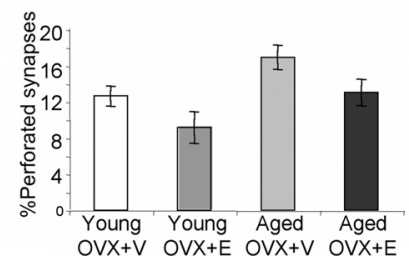

Figure 1. ER- $\alpha$ distribution in axospinous synapses in layer III of area 46. $\boldsymbol{A}$, An electron micrograph showing ER- $\alpha$ immunogold particles in a dendritic spine (SP) and an axon terminal (AT). Scale bar, $100 \mathrm{~nm}$. $\boldsymbol{B}, \mathrm{A}$ bar graph showing the percentage of ER- $\alpha$ labeling in ovariectomized young and aged monkeys treated with $V$ (young $O V X+V$, aged $O V X+V$ ) or $E$ (young $O V X+E$, aged OVX+E). Two-way ANOVA showed an absence of age or treatment effect on the percentage of ER- $\alpha$ labeling ( $p>0.05)$. C, PSD length of ER- $\alpha$-containing AS (344.65 \pm 5.25 $\mathrm{nm}$ ) is larger than non-ER- $\alpha$-containing AS (302.89 \pm 6.73$)$. D, A cumulative frequency demonstrating the size difference between ER- $\alpha$-labeled and -nonlabeled AS. $E$, Age ( $p=0.009$ ) and treatment ( $p=0.016$ ) significantly affect the percentage of total perforated synapses in the PFC.

main are highly likely to be anchored to the synapse, whereas particles $30-60 \mathrm{~nm}$ from the membrane are more likely to be involved with secondary signaling molecules (Spencer et al., 2008).

Statistical analysis. Statistical analyses were performed using SPSS 11.0 (SPSS). Potential age and treatment effects on the percentage of labeled synapses and number of gold particles per synaptic compartment were evaluated by two-way ANOVA. To determine whether the ER- $\alpha$ labeling is preferentially localized to synapses of a specific size, the cumulative frequency distribution of labeled and unlabeled PSD lengths were compared using the Kolmogorov-Smirnov test. Pearson correlations were computed to determine the relationships between ER- $\alpha$ labeling and cognitive performance, and a significance value of 0.0125 was adopted for these analyses to correct for multiple comparisons (four comparisons per analysis).

\section{Results}

The pattern of postembedding immunogold labeling of ER- $\alpha$ in area 46 of female rhesus monkeys was qualitatively similar to previous observations in rat hippocampus (Adams et al., 2002). The majority of gold particles were distributed in axon terminals, typically associated with synaptic vesicles. In the postsynaptic spine, gold particles were occasionally observed within the PSD but more often adjacent to the PSD or within the core of the spine head (Fig. 1A). We determined the percentage of synapses that contained ER- $\alpha$ in layer III of area 46 in all four groups. Approximately $50 \%$ of axospinous synapses were labeled for ER- $\alpha$ in both young and aged monkeys, with or without E (Fig. $1 B$ ). Approximately $57 \%$ of labeled axospinous synapses ( 50 synapses per animal) had ER- $\alpha$ located in both postsynaptic and presynaptic regions, as shown in Figure 1. Approximately 28\% of sampled axospinous synapses had ER- $\alpha$ located only in presynaptic terminals. Approximately 15\% of sampled synapses had ER- $\alpha$ located only in postsynaptic compartments. Two-way ANOVA showed that there was no difference across age and treatment groups in percentage labeling for ER- $\alpha(p>0.05)$ (Fig. $1 B)$. This is in striking contrast to rat CA1, where we previously documented a robust age-related loss of synaptic ER- $\alpha$ (Adams et al., 2002). In general, ER- $\alpha$-labeled synapses were larger than nonlabeled synapses, regardless of age or treatment. PSD length for ER- $\alpha$-containing synapses averaged $( \pm$ SEM) $344.65 \pm 5.25 \mathrm{~nm}$, whereas for non-ER- $\alpha$-containing synapses the average PSD length was $302.89 \pm 6.73$ (Fig. 1C). Kolmogorov-Smirnov test indicated that the cumulative frequency distributions of PSD length were significantly different between ER- $\alpha$-labeled and unlabeled axospinous synapses $\left(p=5.95 \times 10^{-8}\right)$ (Fig. $\left.1 D\right)$. Furthermore, a two-way ANOVA of perforated synapses showed significant age $(p=0.009)$ and treatment $(p=0.016)$ effects such that aged monkeys had a higher percentage of perforated synapses than young monkeys, and E-treated monkeys had a lower percentage than $\mathrm{V}$-treated (Fig. $1 E$ ). We do not interpret this as a direct effect of age and estradiol treatment on the number of perforated synapses, but rather a reflection of a relative shift in the percentage of total axospinous synapses that are perforated due to the loss of small spines with age and the induction of small spines with estradiol treatment (Hao et al., 2007). Perforated synapses are limited to large mushroom spines, which our previous study demonstrated to be relatively stable with respect to age and estradiol treatment.

We next quantified the spatial distribution of ER- $\alpha$ to determine the relative representation in presynaptic terminals compared with postsynaptic spines, as well as within specific postsynaptic domains. This analysis demonstrated that ER- $\alpha$ is distributed widely throughout multiple compartments, with twice as many gold particles in the presynaptic terminals compared with the postsynaptic domains in all groups. We observed no difference in ER- $\alpha$ distribution in any compartment of the synapse as a function of age or treatment $(p>$ 0.05 ; data not shown), revealing a remarkable level of stability across groups.

We then determined whether synaptic ER- $\alpha$ correlated with acquisition or retention on DR across monkeys. There were no significant correlations between DR acquisition (number of trials to learn the task with 0 or $1 \mathrm{~s}$ delay) and percentage of ER- $\alpha$ labeled synapses or number of gold particles per synaptic compartment within any of the groups. We then examined the relationship between DR accuracy across increasingly challenging retention intervals and ER- $\alpha$ labeling. The percentage of ER$\alpha$-labeled synapses in layer III of area 46 had no significant correlation with DR performance (average accuracy across all delay intervals) when all animals were included. However, there was a positive correlation with DR performance in young $\mathrm{OVX}+\mathrm{V}$ animals that we view as a strong trend since it failed to reach the $p$ value required for multiple comparisons (Pearson correlation; $r=0.83, p=0.021$ ), whereas this correlation in the aged $\mathrm{OVX}+\mathrm{V}$ animals was not significant (Pearson correlation; $r=0.735, p=0.060$ ) (Fig. $2 A$ ). There were no correlations between DR performance and the percentage of perforated axospinous synapses (AS) within any of the four groups $(p>0.05)$. 
A
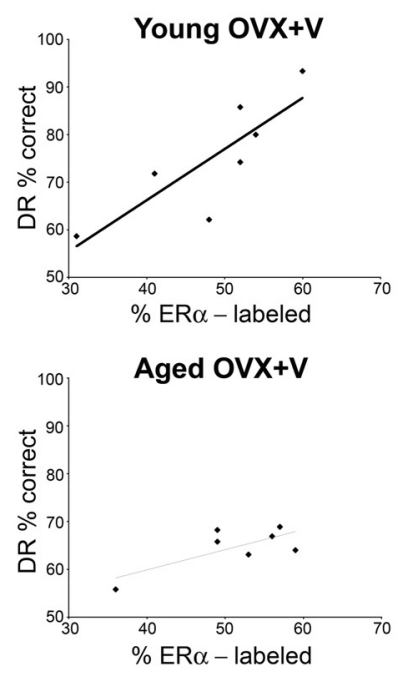

B
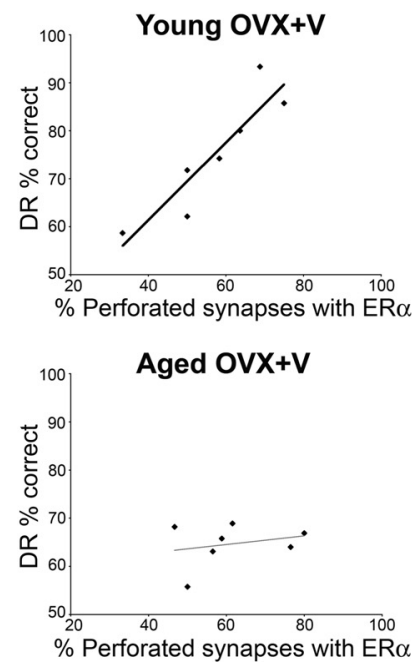
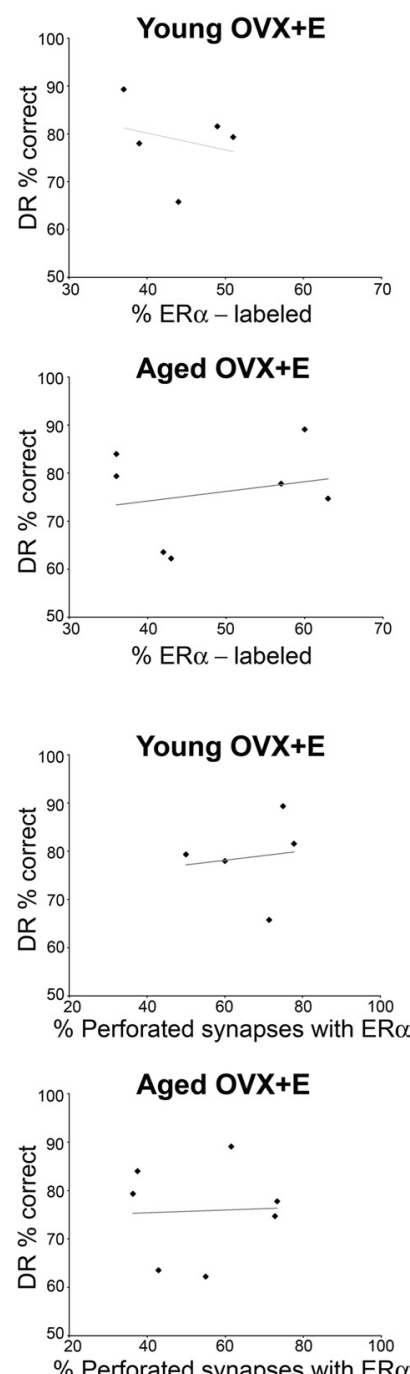

Figure 2. A, A strong correlation between the percentage of ER- $\alpha$ labeling and the DR percentage correct is seen in ovariectomized young monkeys treated with $\mathrm{V}$ (young $0 \mathrm{VX}+\mathrm{V}$; Pearson correlation; $r=0.830, p=0.021)$. $\boldsymbol{B}$, A strong correlation between the percentage of perforated synapses containing ER- $\alpha$ and the DR percentage correct is seen in ovariectomized young monkeys treated with V (young OVX $+\mathrm{V}$; Pearson correlation, $r=0.824, p=0.005$ ).

There were also no correlations between DR performance and the proportion of unlabeled perforated AS within any of the groups $(p>0.05)$. However, the percentage of perforated synapses that contained ER- $\alpha$ was highly correlated with DR performance in the young OVX $+\mathrm{V}$ group (Pearson correlation; $r=0.824, p=$ $0.005)$.

Given that ER- $\alpha$ is present both presynaptically and postsynaptically, we refined the regression analyses to investigate whether presynaptic or postsynaptic ER- $\alpha$ was driving this correlation. The total amount of presynaptic ER- $\alpha$ labeling was strongly coupled with average DR accuracy in the young OVX $+\mathrm{V}$ group (Pearson correlation; $r=0.912, p=0.004$ ) (Fig. 3A). None of the other groups demonstrated a correlation between presynaptic ER- $\alpha$ and DR accuracy ( $p>0.05$ ). In contrast, a striking correlation emerged between DR performance and ER- $\alpha$ in the postsynaptic domain internal to the PSD (i.e., 30-60 nm from the synaptic membrane) that was only present in the aged OVX $+\mathrm{E}$ group (Pearson correlation; $r=0.912, p=$ $0.004)$ (Fig. 3B).
A

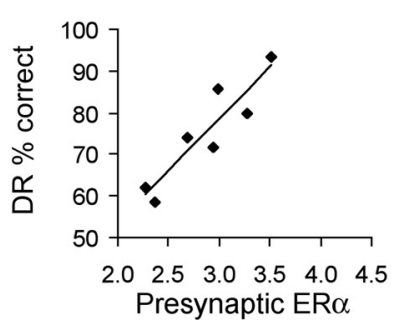

Aged OVX+V

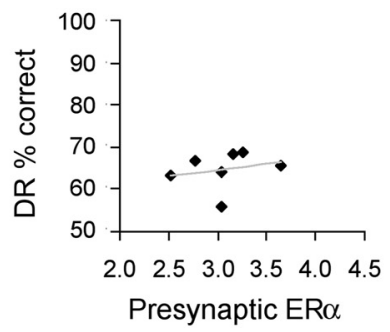

B

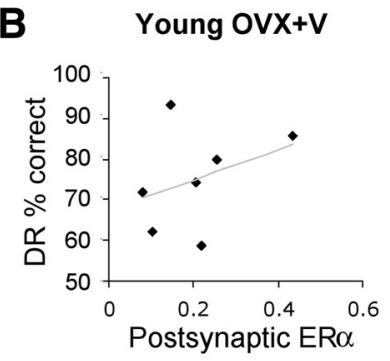

Aged OVX+V

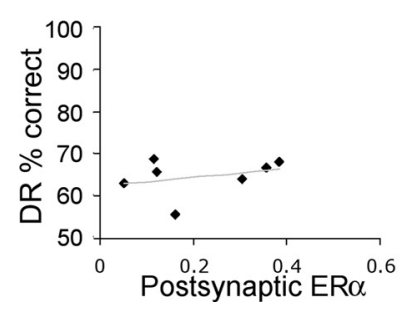

Young OVX+E

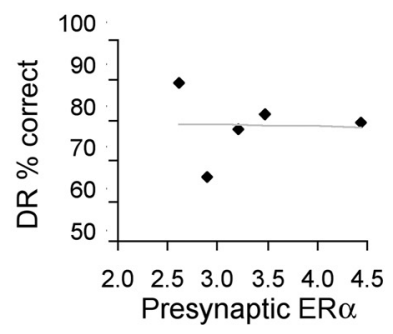

Aged OVX+E

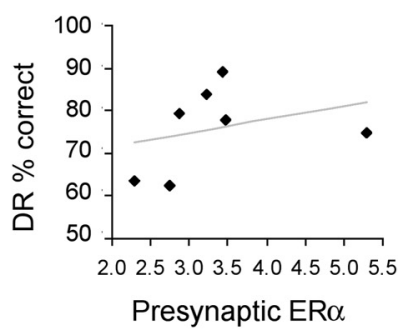

Young OVX+E

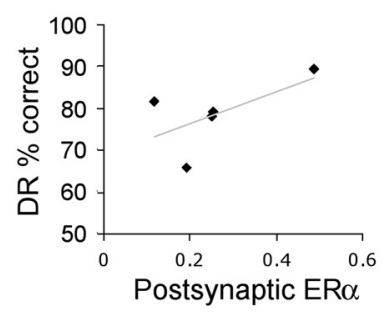

Aged OVX+E

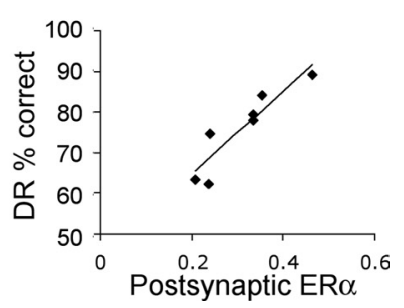

Figure 3. Quantitative analysis of ER- $\alpha$ labeling in presynaptic and postsynaptic domains and correlation with performance on DR. A, Regression analyses correlating the average number of gold particles in presynaptic terminals with DR performance in each group. Note the strong correlation between abundance of presynaptic gold particles and DR performance in young $0 \mathrm{VX}+\mathrm{V}$ (Pearson correlation, $r=0.912, p=0.004$ ). No significant correlation exists in the other three groups $(p>0.5)$. $\boldsymbol{B}$, Regression analyses correlating the average number of gold particles in the postsynaptic domain $30-60 \mathrm{~nm}$ from the synaptic membrane with DR performance in each group. Note the strong correlation between performance on DR and gold particles in the $30-60 \mathrm{~nm}$ bin for the aged $0 \mathrm{VX}+$ Egroup (Pearson correlation, $r=0.912, p=$ 0.004 ) and the lack of such a correlation in the other three groups. No other postsynaptic bin displayed a correlation with DR performance.

\section{Discussion}

Stability of ER- $\alpha$ abundance and distribution in dIPFC regardless of age or treatment

To our knowledge, this is the first report demonstrating that ER- $\alpha$ is present in axospinous synapses in area 46 of monkey neocortex. Approximately $50 \%$ of the axospinous synapses contained ER- $\alpha$, with axon terminals more likely to contain ER- $\alpha$ than spines. Presynaptic ER- $\alpha$ was often associated with vesicles, whereas postsynaptic ER- $\alpha$ was widely distributed in the PSD, adjacent to the PSD, and in the spine core. Importantly, there 
were no age or treatment group effects on either the percentage of synapses labeled for ER- $\alpha$ or its distribution within the synapse. This stability contrasts with rat CA1, where E induced a synaptic redistribution of ER- $\alpha$ in young OVX females, and aged females displayed a dramatic loss of synaptic ER- $\alpha$ (Adams et al., 2002). Although initially puzzling, the comparison of synapse size (i.e., PSD length) in labeled and unlabeled axospinous synapses revealed that this observation is consistent with our previous conclusions in monkey regarding the relative vulnerability of spines/ synapses based on size. In this study, we found that the PSDs in axospinous synapses containing ER- $\alpha$ are significantly larger than unlabeled synapses. PSD length is highly correlated with spine size (Harris and Stevens, 1989), suggesting that ER- $\alpha$ is preferentially localized in relatively large spines. In a previous study with these same animals, we demonstrated that small spines are selectively vulnerable to aging and restored by $\mathrm{E}$ in layer 3 of area 46 (Hao et al., 2007). Thus, the lack of age and treatment effects on ER- $\alpha$-labeled synapses is entirely consistent with our previous spine analyses, since age and treatment effects observed earlier in these same animals were limited to small spines in area 46 . We conclude that ER- $\alpha$ is preferentially present in the class of axospinous synapses that is structurally stable regardless of age or E levels, i.e., larger spines/synapses. ER- $\alpha$ also might stabilize existing small spines or play a role in spine maturation rather than spinogenesis. This conclusion is supported by data on perforated synapses, which are among the largest axospinous synapses. The relative percentage of total axospinous synapses that are perforated is increased with aging and decreased with $\mathrm{E}$. We do not interpret this as a direct effect on the highly stable perforated synapses, but more as a reflection of age-related loss of small spines and an E-induced increase in small spines that lead to a shift in the relative representation of perforated synapses in the total population of axospinous synapses. In addition, ER- $\alpha$ is quite abundant in perforated synapses and, as discussed below, correlated with individual variability in DR performance. Given these findings, the observed relationship between DR performance and synaptic ER- $\alpha$ in young OVX $+V$ animals (see below) is likely unrelated to E-induced spinogenesis, but rather involves the modulation of existing, stable axospinous synapses.

\section{Correlation between cognitive performance and the abundance of synaptic ER- $\alpha$}

Although our results demonstrated compelling correlations between synaptic representation of ER- $\alpha$ in area 46 of monkey dlPFC and individual performance on DR, this association only appears in specific groups. The percentage of ER- $\alpha$-labeled nonperforated axospinous synapses showed a trend toward correlation with performance on DR in the young OVX $+\mathrm{V}$ group. However, labeled perforated synapses correlated strongly with performance on DR in this group, whereas the percentage of total perforated synapses or unlabeled perforated synapses bore no correlation with performance, reinforcing the importance of ER- $\alpha$ in this subclass of synapses with respect to cognitive performance. No correlations between percentage labeled and cognitive performance emerged in any of the other three age/treatment groups. When the analysis was refined and restricted to presynaptic or postsynaptic labeling for ER- $\alpha$, a strong correlation emerged between the abundance of presynaptic ER- $\alpha$ and DR performance in the same young OVX $+\mathrm{V}$ group. A similar correlation between synaptic ER- $\alpha$ and cognitive performance was also present for aged OVX +E monkeys; however, for this group, the correlation was with postsynaptic levels within a specific domain (30-60 nm from synaptic membrane). In addition, al- though scores for the memory components of DR correlated with these synaptic indices, task acquisition was not coupled with any measure of synaptic ER- $\alpha$.

Although it is important to bear in mind that such correlations are not causal, the synapse-behavior correlations in young $\mathrm{OVX}+\mathrm{V}$ monkeys are particularly interesting given that young $\mathrm{OVX}+\mathrm{V}$ monkeys perform as well on DR as those with E, which was not the case with aged OVX monkeys (Hao et al., 2007). Our previous morphologic studies of spine number and size in these same animals highlighted the importance of E-induced, small, highly plastic spines for preserved cognitive function during aging. The current data suggest that performance in young OVX $+\mathrm{V}$ monkey may partially rely on a mechanism other than spinogenesis. Perforated synapses are perhaps the largest and most stable of axospinous synapses (Ganeshina et al., 2004). They clearly represent a very different class of spines from the small, thin spines induced by $\mathrm{E}$ in our previous analyses (Hao et al., 2007). One of the strongest predictors of individual cognitive performance that emerged from this study was the percentage of perforated synapses with ER- $\alpha$ in area 46. Specifically, the percentage of perforated synapses containing ER- $\alpha$ varied from 35 to $80 \%$ in young OVX $+\mathrm{V}$ monkeys, and the correlation coefficient for this synaptic index and DR performance was 0.82 . Our current hypothesis is that, in the absence of circulating E, mechanisms that enhance cognitive performance may operate largely independently of the formation of new synapses and support memory through existing, stable, large, axospinous synapses. In addition, the contribution of these ER- $\alpha$-positive synapses to cognitive performance does not require circulating $\mathrm{E}$ as administered with our treatment. Although our data do not reveal the underlying mechanism(s) for such effects, there are several possibilities. It is conceivable that the synaptic pool of ER- $\alpha$ in young monkeys is activated primarily by intraneuronal E (Rune and Frotscher, 2005), a source that may be increased following OVX (Galmiche et al., 2006). Alternatively, circulating adrenal steroids such as dehydroepiandrosterone (DHEA) may be converted to E (Lasley et al., 2002; MacLusky et al., 2004; Labrie, 2010), which could activate synaptic ER- $\alpha$. DHEA is particularly relevant in this regard, since it is readily converted to $\mathrm{E}$ and it has been proposed that E synthesized from DHEA may serve as a significant source of $\mathrm{E}$ in the absence of gonadal E (MacLusky et al., 2004; Labrie, 2010). It is also possible that E synthesized in adipose tissue contributes sufficiently, since it is a potential source of E in women after menopause (Hemsell et al., 1974; Bulun et al., 1994), though it seems unlikely that this source would generate sufficient levels of $\mathrm{E}$. There is a fourth possibility that involves epidermal growth factor-mediated activation of the mitogenactivated protein kinase pathway, which results in estrogen receptor phosphorylation and activation without a ligand (Kato et al., 1995; Bunone et al., 1996). In contrast, aged OVX monkeys are more reliant on circulating $\mathrm{E}$ to sustain cognitive function, consistent with the finding that the abundance of postsynaptic ER- $\alpha$ correlates with DR performance among aged OVX $+\mathrm{E}$ monkeys. The postsynaptic domain $30-60 \mathrm{~nm}$ from the synaptic membrane is of particular importance because ER- $\alpha$ in this location is ideally suited to link synaptic receptor activity to signaling cascades involved with spine/synapse formation (Spencer et al., 2008). Finally, it will be important to pursue other ERs at the ultrastructural level in monkey area 46 , such as ER- $\beta$, which has been shown to induce spines and improve cognition in a rodent model (Liu et al., 2008), and/or GPR30, which mediates E effects through G-protein coupled signaling (Prossnitz et al., 2008). 
These receptors may be more appropriately positioned to mediate spinogenesis in area 46 than ER- $\alpha$.

\section{Individual variation in synaptic ER- $\alpha$ and implication for hormone therapy}

These correlations between synaptic ER- $\alpha$ and cognitive performance have important implications for therapeutic strategies for both surgically menopausal young women and women who are in the menopausal transition. There is considerable variability among women with respect to perimenopausal symptoms, and symptom onset does not correlate well with circulating E levels (Skurnick et al., 2009). In addition, the effectiveness of hormone therapy is now thought to depend on the formulation and timing of administration (Maki, 2006; Sherwin, 2006; Sherwin and Henry, 2008; Maki and Sundermann, 2009). Our data suggest that individual variation in levels of synaptic ER- $\alpha$ might be partially responsible for the variability in the cognitive response to menopause and hormone therapy in women. In addition, targeting brain ER- $\alpha$ through synthetic or naturally occurring agonists or E precursors such as DHEA may be very promising with respect to improving cognitive function as an alternate to systemic E replacement (Labrie, 2010). Targeting ER- $\alpha$ is consistent with a study showing improvement of spatial learning in ER- $\alpha$ knockout mice with viral vector-mediated delivery of ER- $\alpha$ to the hippocampus (Foster et al., 2008). The current results from our NHP model have important implications for understanding variability in both vulnerability to E depletion and response to hormone treatment for women with surgical ovariectomies and naturally occurring ovarian hormone decline.

\section{References}

Adams MM, Shah RA, Janssen WG, Morrison JH (2001) Different modes of hippocampal plasticity in response to estrogen in young and aged female rats. Proc Natl Acad Sci U S A 98:8071-8076.

Adams MM, Fink SE, Shah RA, Janssen WG, Hayashi S, Milner TA, McEwen BS, Morrison JH (2002) Estrogen and aging affect the subcellular distribution of estrogen receptor-alpha in the hippocampus of female rats. J Neurosci 22:3608-3614.

Adams MM, Fink SE, Janssen WG, Shah RA, Morrison JH (2004) Estrogen modulates synaptic $N$-methyl-D-aspartate receptor subunit distribution in the aged hippocampus. J Comp Neurol 474:419-426.

Blackstad TW, Karagülle T, Ottersen OP (1990) MORFOREL, a computer program for two-dimensional analysis of micrographs of biological specimens, with emphasis on immunogold preparations. Comput Biol Med 20:15-34.

Brann DW, Dhandapani K, Wakade C, Mahesh VB, Khan MM (2007) Neurotrophic and neuroprotective actions of estrogen: basic mechanisms and clinical implications. Steroids 72:381-405.

Brinton RD (2009) Estrogen-induced plasticity from cells to circuits: predictions for cognitive function. Trends Pharmacol Sci 30:212-222.

Bulun SE, Mahendroo MS, Simpson ER (1994) Aromatase gene expression in adipose tissue: relationship to breast cancer. J Steroid Biochem Mol Biol 49:319-326.

Bunone G, Briand PA, Miksicek RJ, Picard D (1996) Activation of the unliganded estrogen receptor by EGF involves the MAP kinase pathway and direct phosphorylation. EMBO J 15:2174-2183.

Chaudhry FA, Lehre KP, van Lookeren Campagne M, Ottersen OP, Danbolt NC, Storm-Mathisen J (1995) Glutamate transporters in glial plasma membranes: highly differentiated localizations revealed by quantitative ultrastructural immunocytochemistry. Neuron 15:711-720.

Foster TC, Rani A, Kumar A, Cui L, Semple-Rowland SL (2008) Viral vector-mediated delivery of estrogen receptor-alpha to the hippocampus improves spatial learning in estrogen receptor-alpha knockout mice. Mol Ther 16:1587-1593.

Frick KM (2009) Estrogens and age-related memory decline in rodents: what have we learned and where do we go from here? Horm Behav $55: 2-23$.
Gallagher M, Rapp PR (1997) The use of animal models to study the effects of aging on cognition. Annu Rev Psychol 48:339-370.

Galmiche G, Richard N, Corvaisier S, Kottler ML (2006) The expression of aromatase in gonadotropes is regulated by estradiol and gonadotropinreleasing hormone in a manner that differs from the regulation of luteinizing hormone. Endocrinology 147:4234-4244.

Ganeshina O, Berry RW, Petralia RS, Nicholson DA, Geinisman Y (2004) Differences in the expression of AMPA and NMDA receptors between axospinous perforated and nonperforated synapses are related to the configuration and size of postsynaptic densities. J Comp Neurol 468:86-95.

Gilardi KV, Shideler SE, Valverde CR, Roberts JA, Lasley BL (1997) Characterization of the onset of menopause in the rhesus macaque. Biol Reprod 57:335-340.

Hao J, Rapp PR, Leffler AE, Leffler SR, Janssen WG, Lou W, McKay H, Roberts JA, Wearne SL, Hof PR, Morrison JH (2006) Estrogen alters spine number and morphology in prefrontal cortex of aged female rhesus monkeys. J Neurosci 26:2571-2578.

Hao J, Rapp PR, Janssen WG, Lou W, Lasley BL, Hof PR, Morrison JH (2007) Interactive effects of age and estrogen on cognition and pyramidal neurons in monkey prefrontal cortex. Proc Natl Acad Sci USA 104:11465-11470.

Harris KM, Stevens JK (1989) Dendritic spines of CA 1 pyramidal cells in the rat hippocampus: serial electron microscopy with reference to their biophysical characteristics. J Neurosci 9:2982-2997.

Hemsell DL, Grodin JM, Brenner PF, Siiteri PK, MacDonald PC (1974) Plasma precursors of estrogen. II. Correlation of the extent of conversion of plasma androstenedione to estrone with age. J Clin Endocrinol Metab 38:476-479.

Hjelle OP, Chaudhry FA, Ottersen OP (1994) Antisera to glutathione: characterization and immunocytochemical application to the rat cerebellum. Eur J Neurosci 6:793-804.

Hojo Y, Hattori TA, Enami T, Furukawa A, Suzuki K, Ishii HT, Mukai H, Morrison JH, Janssen WG, Kominami S, Harada N, Kimoto T, Kawato S (2004) Adult male rat hippocampus synthesizes estradiol from pregnenolone by cytochromes P45017alpha and P450 aromatase localized in neurons. Proc Natl Acad Sci U S A 101:865-870.

Hojo Y, Murakami G, Mukai H, Higo S, Hatanaka Y, Ogiue-Ikeda M, Ishii H, Kimoto T, Kawato S (2008) Estrogen synthesis in the brain: role in synaptic plasticity and memory. Mol Cell Endocrinol 290:31-43.

Joffe H, Hall JE, Gruber S, Sarmiento IA, Cohen LS, Yurgelun-Todd D, Martin KA (2006) Estrogen therapy selectively enhances prefrontal cognitive processes: a randomized, double-blind, placebo-controlled study with functional magnetic resonance imaging in perimenopausal and recently postmenopausal women. Menopause 13:411-422.

Kato S, Endoh H, Masuhiro Y, Kitamoto T, Uchiyama S, Sasaki H, Masushige S, Gotoh Y, Nishida E, Kawashima H, Metzger D, Chambon P (1995) Activation of the estrogen receptor through phosphorylation by mitogenactivated protein kinase. Science 270:1491-1494.

Labrie F (2010) DHEA, important source of sex steroids in men and even more in women. Prog Brain Res 182:97-148.

Lasley BL, Santoro N, Randolf JF, Gold EB, Crawford S, Weiss G, McConnell DS, Sowers MF (2002) The relationship of circulating dehydroepiandrosterone, testosterone, and estradiol to stages of the menopausal transition and ethnicity. J Clin Endocrinol Metab 87:3760-3767.

Ledoux VA, Smejkalova T, May RM, Cooke BM, Woolley CS (2009) Estradiol facilitates the release of neuropeptide $\mathrm{Y}$ to suppress hippocampusdependent seizures. J Neurosci 29:1457-1468.

Liu F, Day M, Muñiz LC, Bitran D, Arias R, Revilla-Sanchez R, Grauer S, Zhang G, Kelley C, Pulito V, Sung A, Mervis RF, Navarra R, Hirst WD, Reinhart PH, Marquis KL, Moss SJ, Pangalos MN, Brandon NJ (2008) Activation of estrogen receptor-beta regulates hippocampal synaptic plasticity and improves memory. Nat Neurosci 11:334-343.

MacLusky NJ, Hajszan T, Leranth C (2004) Effects of dehydroepiandrosterone and flutamide on hippocampal CA1 spine synapse density in male and female rats: implications for the role of androgens in maintenance of hippocampal structure. Endocrinology 145:4154-4161.

Maki PM (2006) Hormone therapy and cognitive function: is there a critical period for benefit? Neuroscience 138:1027-1030.

Maki PM, Sundermann E (2009) Hormone therapy and cognitive function. Hum Reprod Update 15:667-681.

Milner TA, McEwen BS, Hayashi S, Li CJ, Reagan LP, Alves SE (2001) 
Ultrastructural evidence that hippocampal alpha estrogen receptors are located at extranuclear sites. J Comp Neurol 429:355-371.

Morrison JH, Brinton RD, Schmidt PJ, Gore AC (2006) Estrogen, menopause, and the aging brain: how basic neuroscience can inform hormone therapy in women. J Neurosci 26:10332-10348.

Park CS, Elgersma Y, Grant SG, Morrison JH (2008) Alpha-isoform of calciumcalmodulin-dependent protein kinase II and postsynaptic density protein 95 differentially regulate synaptic expression of NR2A- and NR2B-containing $\mathrm{N}$-methyl-D-aspartate receptors in hippocampus. Neuroscience 151:43-55.

Prossnitz ER, Arterburn JB, Smith HO, Oprea TI, Sklar LA, Hathaway HJ (2008) Estrogen signaling through the transmembrane G proteincoupled receptor GPR30. Annu Rev Physiol 70:165-190.

Rapp PR, Morrison JH, Roberts JA (2003) Cyclic estrogen replacement improves cognitive function in aged ovariectomized rhesus monkeys. J Neurosci 23:5708-5714.

Rune GM, Frotscher M (2005) Neurosteroid synthesis in the hippocampus: role in synaptic plasticity. Neuroscience 136:833-842.

Ruud HK, Blackstad TW (1999) PALIREL, a computer program for analyzing particle-to-membrane relations, with emphasis on electron micrographs of immunocytochemical preparations and gold labeled molecules. Comput Biomed Res 32:93-122.

Selvamani A, Sohrabji F (2010) The neurotoxic effects of estrogen on ischemic stroke in older female rats is associated with age-dependent loss of insulin-like growth factor-1. J Neurosci 30:6852-6861.

Sherwin BB (2006) Estrogen and cognitive aging in women. Neuroscience 138:1021-1026.
Sherwin BB, Henry JF (2008) Brain aging modulates the neuroprotective effects of estrogen on selective aspects of cognition in women: a critical review. Front Neuroendocrinol 29:88-113.

Shideler SE, Gee NA, Chen J, Laughlin LS, Rapp PR, Morrison JH, Roberts JA, Moran FM, Lasley BL (2003) Contribution of ovarian steroid production to urinary estrone conjugate concentrations in Macaca mulatta. Am J Primatol 61:111-121.

Skurnick JH, Weiss G, Goldsmith LT, Santoro N, Crawford S (2009) Longitudinal changes in hypothalamic and ovarian function in perimenopausal women with anovulatory cycles: relationship with vasomotor symptoms. Fertil Steril 91:1127-1134.

Spencer JL, Waters EM, Romeo RD, Wood GE, Milner TA, McEwen BS (2008) Uncovering the mechanisms of estrogen effects on hippocampal function. Front Neuroendocrinol 29:219-237.

van Lookeren Campagne M, Oestreicher AB, van der Krift TP, Gispen WH, Verkleij AJ (1991) Freeze-substitution and Lowicryl HM20 embedding of fixed rat brain: suitability for immunogold ultrastructural localization of neural antigens. J Histochem Cytochem 39:1267-1279.

Voytko ML, Murray R, Higgs CJ (2009) Executive function and attention are preserved in older surgically menopausal monkeys receiving estrogen or estrogen plus progesterone. J Neurosci 29:10362-10370.

Yildirim M, Janssen WG, Tabori NE, Adams MM, Yuen GS, Akama KT, McEwen BS, Milner TA, Morrison JH (2008) Estrogen and aging affect synaptic distribution of phosphorylated LIM kinase (pLIMK) in CA1 region of female rat hippocampus. Neuroscience 152:360-370. 